\title{
Phenotype and maturation rate of oocytes of chimaeric mice produced from two strains that differ in oocyte quality
}

\author{
B. Wabik-Śliz \\ Department of Genetics and Evolution, Jagiellonian University, 30-060 Cracow, Poland
}

\begin{abstract}
The oocytes of females from the inbred mouse strains KE (albino) and CBA (agouti) differ in the following characteristics: the appearance of the cytoplasm is clear in KE but granular in CBA; the cumulus oophorus dispersion with hyaluronidase is quick in $\mathrm{KE}$ but slow in $\mathrm{CBA}$; dissolution of the zona pellucida with a proteolytic enzyme is slow in $\mathrm{KE}$ but quick in $\mathrm{CBA}$; and the maturation stage at the time of ovulation is metaphase I in KE while in CBA the first polar body has been extruded. Aggregation chimaeras were produced to investigate whether these differences are intrinsic or extrinsic to developing oocytes. Among 13 fertile chimaeric females, two produced only CBA oocytes, four produced both $\mathrm{CBA}$ and $\mathrm{KE}$ oocytes and were germline chimaeras, and seven produced only KE oocytes, as recognized by progeny testing. The larger number of females producing $\mathrm{KE}$ oocytes is a result of strong selection against $\mathrm{CBA}$ germ cells. All chimaeric females had cumuli composed of both KE and CBA cells, as recognized by the time of dispersion and glucose phosphate isomerase electrophoresis, but the presence of non-homologous cumulus cells did not change the character of the developing oocytes significantly. The conclusion from this study is that the rate of meiotic maturation, sensitivity of oocyte investments to enzymes, and deposition of granules in ooplasm are determined largely autonomously by genes acting in the germ cells.
\end{abstract}

\section{Introduction}

The inbred strains of mice used in this study, CBA and $\mathrm{KE}$, differ greatly in several properties of the oocyte related to fertility: the efficiency of fertilization in vivo (Krzanowska, 1970) and in vitro (Kaleta, 1977), the number of cortical granules in ovulated oocytes (Wabik-Śliz, 1979), and the rate of cumulus oophorus dispersion and zona pellucida dissolution (Krzanowska, 1972; Kaleta and Polak, 1978). The ovulated oocytes of the KE strain have a cumulus oophorus that is loose in appearance and quickly dispersed with hyaluronidase, the zona pellucida of $\mathrm{KE}$ oocytes is resistant and difficult to dissolve with proteolytic enzymes, and the cytoplasm is clear and transparent. In the CBA strain, cumulus cells are compact and disperse slowly with hyaluronidase, zonae pellucidae are very sensitive to the action of proteolytic enzymes, and the cytoplasm of CBA oocytes is granular and dark (for review, see Wabik-Śliz, 1986). Genetic analysis has revealed that these characters segregate in $\mathrm{F}_{2}$ hybrids between $\mathrm{KE}$ and $\mathrm{CBA}$ strains (Kaleta and Majewska, 1979; Wabik-Sliz, 1986). A difference in oocyte maturation rate has also been found: at the time of ovulation ( $11 \mathrm{~h}$ after $\mathrm{hCG}$ injection) the oocytes of KE mice are still in metaphase I, while the oocytes of CBA females began to extrude the first polar body $3 \mathrm{~h}$ earlier, before ovulation (Krzanowska et al., 1984; Polański, 1986).

The developing oocyte is in very close contact with cumulus cells, and the gap junctions between oocyte and cumulus cells

Received 26 July 1996 allow for reciprocal metabolic cooperativity (Gilula et al., 1978). It seems that this coupling plays an important role in the control of resumption of meiosis by the oocyte (Eppig, 1982; Eppig et al., 1983; Schultz et al., 1983) but it is unclear whether other oocyte properties are controlled autonomously by the genotype of the oocyte or by the somatic follicular cells surrounding the oocyte. This question could be answered using $\mathrm{KE}-\mathrm{CBA}$ chimaeric mice.

The embryo aggregation chimaeras provide a very special situation in which the developing gonads containing somatic tissue of two genetic types are colonized by germ cells of two genetic types. For this reason, chimaeras might be particularly useful in studies of germ-cell development, primary sex differentiation, and distribution of functional germ cells (McLaren, 1976; Gearhart and Oster-Granite, 1981; lannaccone et al., 1985). The female chimaera may contain some oocytes surrounded by follicles consisting wholly or partly of cells of the other component. This may or may not have consequences for gamete phenotype, depending on whether the characters are autonomously controlled by the genotype of a germ cell.

The study of KE-CBA chimaeric males has shown that the shape of the heads of spermatozoa, the extent of sperm abnormalities, and their fertilizing capacity are determined largely autonomously by genes acting in the germ cells. Somatic cells of a different genotype create the internal environment but this causes only minor modifications (Krzanowska et al., 1991). The similar autonomy of germline genes was also found in C57BL-C3H male chimaeras (Burgoyne, 1975). 
The present experiment was designed to investigate whether the somatic cells of one genotype in the ovary of chimaeric females could influence the features of the oocyte of a different genotype.

\section{Materials and Methods}

\section{Animals}

Three inbred mouse strains were used to construct aggregation chimaeras: $\mathrm{KE}$ (albino), $\mathrm{CBA} / \mathrm{Kw}$ and $\mathrm{CBA} / \mathrm{HT} 6$. Both $\mathrm{CBA} / \mathrm{Kw}$ and $\mathrm{CBA} / \mathrm{HT} 6$ are agouti; and $\mathrm{CBA} / \mathrm{HT} 6$ carries the $\mathrm{T}(14 ; 15) 6 \mathrm{Ca}$ translocation (Festing, 1993); these strains are referred to as CBA and CBAT6, respectively. All three strains express a different isoform of the enzyme glucose phosphate isomerase (GPI-1; EC 5.3.1.9.): KE mice express the alloenzyme $\mathrm{A}$, while mice from both CBA strains express the alloenzyme $\mathrm{B}$ (Rafiński and Krzanowska, 1985).

\section{Production and testing of chimaeras}

The chimaeras were obtained by aggregating four-eight-cell embryos according to the method described by Bowman and McLaren (1970), with slight modifications reported by Krzanowska et al. (1991). The chimaeric pups were identified by their dark (agouti) and white patched coat colour, and at weaning were scored for the proportion of the agouti patches of their fur.

Mature overt female chimaeras were mated with unrelated albino males (not KE to avoid any possible disadvantage of inbred KE embryos in competition with hybrid ones) and the offspring were scored for eye pigmentation at birth: the young born from KE oocytes had unpigmented eyes, while those from CBA or CBAT6 oocytes had pigmented eyes. Only fertile females were taken for analysis in this study. At the end of the experiment, bone marrow preparations were made for each female, according to the method described by Lenartowicz et al. (1988), to estimate their karyotypes.

\section{Analysis of ovulated oocytes}

After chimaeric females had given birth to four or five litters, they were superovulated by injecting 5 iu pregnant mares' serum gonadotrophin (PMSG), followed by 5 iu hCG 48-50 h later. The females were anaesthetized with Vetbutal (sodium pentobarbiturate; Pulawskie Zaklady Przemyslu Weterynaryjnego, Poland) $15-16 \mathrm{~h}$ after hCG injection and their oviducts were removed. The clusters of ovulated oocytes, freed by puncturing the ampullae, were divided mechanically into single oocyte-cumulus-cell complexes, and each was placed in a separate PBS drop containing 10 iu bovine testicular hyaluronidase (Sigma, St Louis, MO) under paraffin oil at $37^{\circ} \mathrm{C}$. The time required for granulosa cell dispersal was monitored for each oocyte. The cumulus of the oocyte was classified according to the time of dispersal as KE-like $(0-11 \mathrm{~min})$ intermediate (12-16 min), or CBA-like ( $\geq 17 \mathrm{~min})$. These classes were distinguishable because in the KE strain more than
$90 \%$ of cumuli dispersed within the first time interval and only $0.6 \%$ within the last interval (Table 1 ).

After $25 \mathrm{~min}$ the cumulus cells from each denuded oocyte were collected separately and analysed for GPI isoforms by electrophoresis. For KE-CBA chimaeras, starch gels were used, as described by Krzanowska et al. (1991), while the electrophoresis of samples from KE-CBAT6 chimaeras was run on gel-acetate plates (Chemerton, Milan). The gels and plates were stained for GPI activity according to the method of Harris and Hopkinson (1976). Unfortunately, the results were not clear for cumuli of ovulated ova for five chimaeras and for ovarian cumuli of two females (indicated as 'no data' in Table I).

The denuded oocytes were washed and transferred separately to PBS drops containing 3 iu $\alpha$-chymotrypsin to test the solubility of the zonae pellucida. The time required for zona pellucida digestion was monitored for each oocyte for $60 \mathrm{~min}$, and the oocytes were divided accordingly into three groups: KE-like (>30 min), intermediate (15-29 min) and CBA-like ( $0-14 \mathrm{~min}$ ). More than $80 \%$ of pure KE and CBA oocytes were denuded in the time intervals adopted for KE-like and CBA-like groups. Each oocyte was also classified according to the appearance of the cytoplasm: clear (KE strain), granular (CBA and CBAT6 strains), or intermediate.

\section{Analysis of ovarian oocytes}

Two to four weeks after the first operation the female chimaeras were treated with PMSG and hCG again. These mice were killed $10 \mathrm{~h}$ after hCG administration and their ovaries dissected. The oocytes were isolated by puncturing the largest follicles, released mechanically from cumulus cells, placed on a microscope slide and allowed to dry, and then fixed with ethanol + glacial acetic acid (3:1), and stained with $1 \%$ toluidine blue. The stage of meiotic maturation of each oocyte was established under the microscope on the basis of the presence or absence of the first polar body and the arrangement of chromosomes in the oocyte. Oocytes with the first polar body extruded or in anaphase I were recognized as CBA; while oocytes in metaphase I, without a polar body, were classified as $\mathrm{KE}$. The granulosa cells of each ovarian oocyte were used for GPI analysis, as for ovulated oocytes. Five categories of cumulus were distinguished, depending on the cell composition (revealed by GPI analysis): only KE, only CBA, mixed cells with more from $K E$ than $C B A$, mixed cells with more from $\mathrm{CBA}$ than $\mathrm{KE}$, and cumuli with equal proportions of $\mathrm{KE}$ and CBA cells.

\section{Results}

Thirteen fertile, overtly chimaeric, females were examined. Although they differed markedly in the degree of coat colour chimaerism (Table 1), the majority of them had germ cells from only one cell line. There were no germline chimaeras among KE-CBA chimaeric females. Five of these females, with $60-98 \%$ of their coats being albino, produced only albino pups from $\mathrm{KE}$ oocytes (female numbers 5, 48, 54, 55 and 16). The other two KE-CBA chimaeras (with $85-95 \%$ of their fur being agouti) produced only agouti pups, from $\mathrm{CBA}$ oocytes 


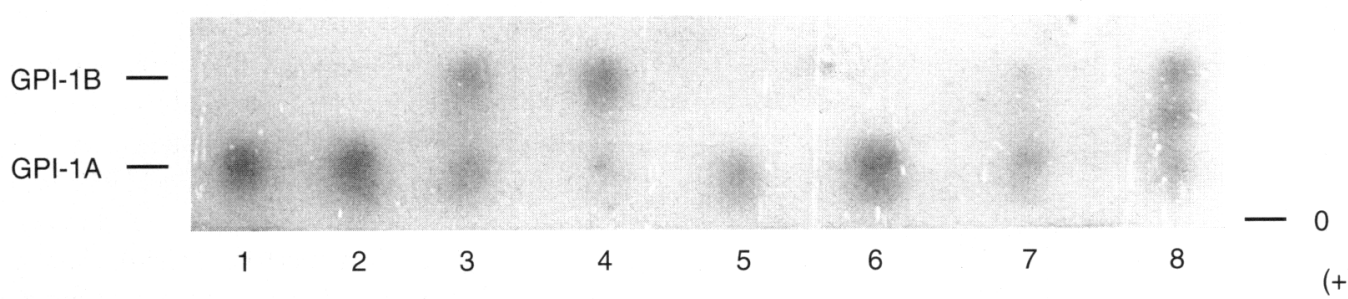

Fig. 1. Expression of glucose phosphate isomerase (GPI-1) in granulosa cells from ovarian oocytes of chimaeric mouse number 16. The first seven lanes in the gel contain samples of granulosa cells from single oocytes. Lane number 8 contains the control substance GPI-1AB.

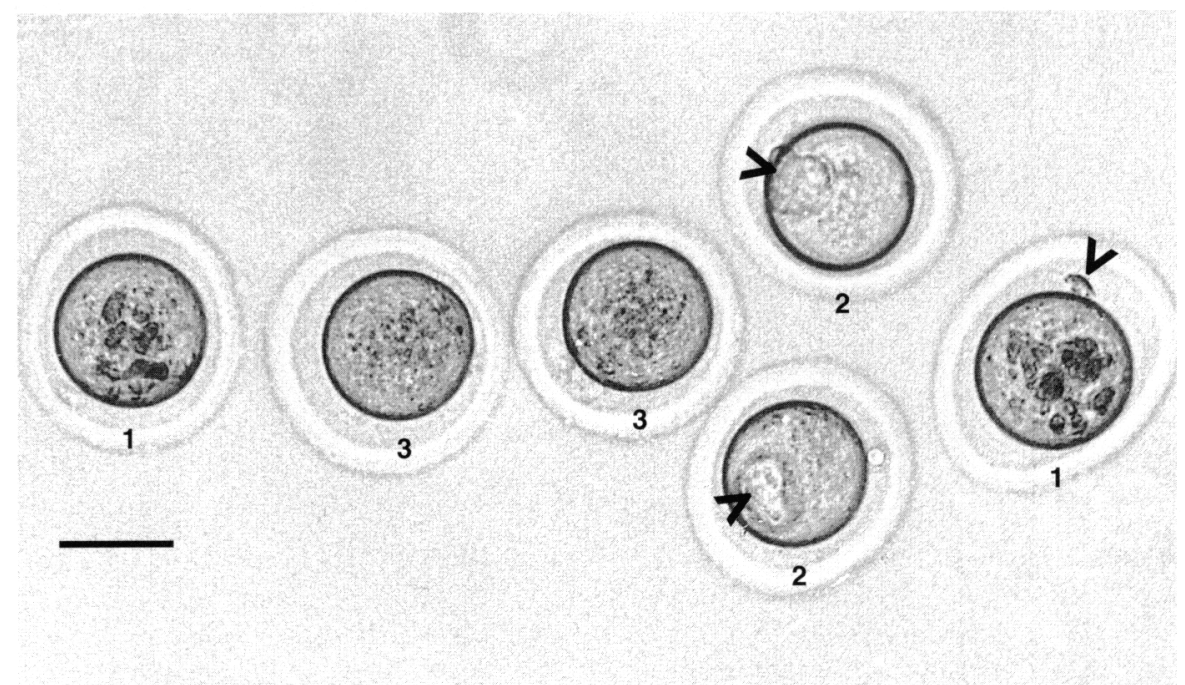

Fig. 2. Oocytes from chimaeric mice showing different granularity of the cytoplasm. Those marked (1) are granular from strain CBA, (2) indicates clear cytoplasm from strain KE, while (3) shows cytoplasm of intermediate granularity. Arrows indicate polar bodies. Scale bar represents $50 \mu \mathrm{m}$.

(chimaera numbers 57 and 58). Analysis of mitotic metaphases from bone marrow revealed that chimaeric females $54,55,57$ and 58 were composed of $X X$ and $X Y$ cells. Unfortunately, for technical reasons, the cytological tests were not possible for the three other chimaeric females of this type. However, among six chimaeric females developed from KE and CBAT6 embryos, four were $X X-X X$ chimaeras and produced progeny from both $\mathrm{CBA}$ and $\mathrm{KE}$ components, although predominantly from KE cells. The remaining two KE-CBAT6 females had germ cells of one type only and gave birth exclusively to albino pups. One of them, number 79 , was karyotyped as $X X-X X$. Clear karyotyping was not possible for female number 72 .

The analysis of GPI-1 alloenzymes in the cumulus oophorus showed some chimaerism of the somatic tissue of the ovary, both in $X X-X X$ and $X X-X Y$ chimaeras (Table $1 ;$ Fig. I). In all chimaeric females, there were 20 ovarian oocytes with their cumuli composed of both $\mathrm{KE}$ and $\mathrm{CBA}$ cells. The correlation between the proportion of the two types of cell in the cumulus and the granularity of the cytoplasm of the oocyte (both characters were given arbitrarily chosen values; Fig. 2) was not significant $(F=1.30, P=0.27)$. The granulosa dispersal test also showed the chimaerism of different cumuli. However, the correlation between the genotype of the cumulus cells (revealed by GPI analysis) and the time of their dispersal was not significant $(F=1.25, P=0.27)$, as calculated for 42 single cumuli for which complete data were available.

\section{Chimaeras producing only albino pups}

In these females (numbers 5, 48,54, 55, 16, 79 and 72), cumulus chimaerism was shown by GPI analysis (Table 1 ) and in a cumulus dispersal test of ovulated oocytes: 29 showed a short dispersal time like KE cumuli, seven were intermediate and seven were CBA-like. In spite of this, oocytes behaved mainly as $\mathrm{KE}$ cells in the zona digestion test and in their maturation rate (Table 1 ). The test of independence revealed no difference between the oocytes of chimaeric females and KE females for their distribution of maturation stages $\left(\chi^{2}=0.35\right.$; d.f. $=1 ; P=0.55$ ). Among chimaeric females there were no oocytes classified as intermediate on the basis of zona digestion times, even though such oocytes were observed in the pure KE females. However, a few oocytes from chimaeric females showed some granulation of the cytoplasm, which never occurred in the KE strain. This suggests an influence of CBA-derived granulosa cells on oocyte cytoplasm. However, 
B. Wabik-Śliz

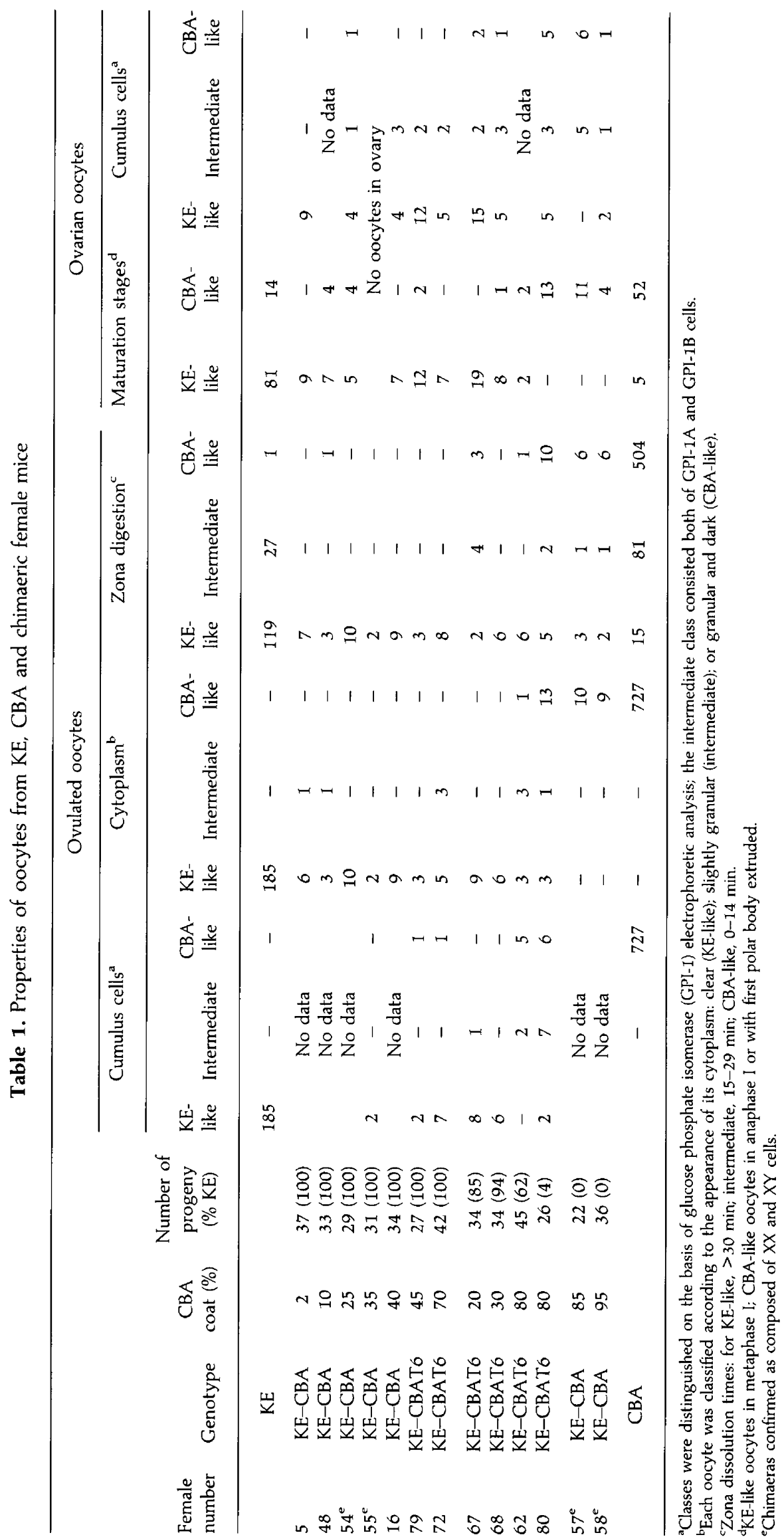


there was no significant correlation between the times required for cumulus cell dispersion and the type of the cytoplasm (in arbitrary values) for individual oocyte-cumulus complexes $(r=0.30 ;$ d.f. $=26 ; P=0.12)$.

\section{Chimaeras producing only agouti pups}

Although the cumuli in these females (numbers 57 and 58) were composed of both $\mathrm{KE}$ and CBA cells (Table $\mathrm{I}$; the test of cumulus dispersal showed nine cumuli to be CBA-like, ten to be intermediate and none to be KE-like), both the type of cytoplasm and the stage of oocyte maturation were typical for the CBA strain. However, the distribution of zona digestion times in chimaeras was significantly different from that in the CBA strain $\left(\chi^{2}=33.41\right.$; d.f. $\left.=2 ; P<0.001\right)$, showing the influence of the $\mathrm{KE}$ somatic component.

\section{Chimaeras producing both agouti and albino progeny}

In these females (numbers 67, 68, 62 and 80), the proportions of oocytes showing characteristics typical for either the $\mathrm{KE}$ or CBA strain closely resembled the proportions of albino and agouti pups in their progeny.

\section{Discussion}

The properties of the cumulus cells and oocytes of the inbred mouse strains $\mathrm{KE}$ and $\mathrm{CBA}$ or CBAT6 are very different. The analysis of GPI-1 alloenzymes showed that cumulus masses of chimaeric females were composed of different proportions of cells belonging to $\mathrm{KE}$ or $\mathrm{CBA}$ genotypes. The various degrees of chimaerism in the cumulus may not be in agreement with the degree of chimaerism in the germ line.

The majority of chimaeric females examined produced oocytes from one component only. Some of them were shown to be $X X-X Y$ chimaeras, and from these females mixed progeny would not be expected because it is known that only few, if any, $X Y$ germ cells can develop into functional oocytes (Ford et al., 1975; Evans et al., 1977; McLaren, 1991). We assumed that at least some of the other chimaeric females that produced exclusively albino pups could be $X X-X X$ but had functional oocytes of KE strain origin only, as a result of a strong selection against CBA germ cells. Such a selection was revealed in KE-CBA male chimaeras (Krzanowska ef al., 1991); all $X Y-X Y$ males, even those with $90 \%$ of their coat being CBA, produced no more than $4.5 \%$ of CBA spermatozoa. Similar germ-cell selection was described for some other strain combinations (Mintz, 1968). This selection seems to be weaker in KE-CBAT6 chimaeric females. Four of six such females produced progeny from both CBAT6 and KE components, but predominantly from $\mathrm{KE}$ cells. These females also produced two types of granulosa cell but the influence of the foreign somatic cells on the germ cells appeared to be negligible, because the proportion of oocytes with $\mathrm{KE}$ or $\mathrm{CBA}$ characteristics was very close to the proportion of albino and agouti pups in the progeny of respective females.

In females that produced one type of oocyte exclusively, the presence of foreign somatic cells in proximity to or in contact with the developing oocyte also had very little influence on the oocyte. The presence of a few oocytes with slightly granular cytoplasm in chimaeric females producing only KE oocytes suggests the influence of the CBA-derived somatic component; however, the lack of correlation between the type of cytoplasm of the oocytes and the genotype of cumulus cells seems to suggest an influence of the general environment rather than a direct influence of the cumulus cells surrounding the developing oocyte.

Dong et al.(1996) described a factor secreted by the oocyte that controls proliferation and other properties of granulosa cells. Our results do not show any clear influence of the oocyte on the cumulus cells of a different genotype. In some cases, the cumulus dispersal results were not in agreement with the genotype of the cumulus cells revealed by GPI enzyme analysis but this aiso could be regarded as the influence of the general environment.

In the females producing only KE progeny, the low sensitivity to chymotrypsin of the zona pellucida from the KE-derived oocytes was not changed under the influence of CBA-derived cumulus cells. However, in females producing only CBA progeny, the high sensitivity to chymotrypsin of CBA-derived oocytes was slightly decreased: the proportion of oocytes with zonae more resistant to enzyme digestion was higher than in the pure CBA strain, possibly as a consequence of $\mathrm{KE}$ derived cells in the cumulus. For example, although zona glycoproteins are produced by the oocyte, gap junctions between cumulus cells and oocytes provide a means whereby the somatic cell might modulate oocyte biosynthesis and metabolic activity.

The maturation rate is clearly mediated by oocyte-cumulus coupling (Eppig, 1982; Racowsky and Satterlie, 1985). The distinct difference in the time of resumption of meiosis observed in preovulatory $\mathrm{KE}$ and CBA oocytes was still retained in cultured, cumulus-free oocytes in vitro, isolated from the ovaries of $\mathrm{KE}$ and CBA females at the metoestrous phase of the cycle (Polan'ski, 1986). Therefore, if the rate of oocyte maturation is influenced by somatic components of the follicle at some earlier stages of follicle development, the KE and CBA oocytes in chimaeric female ovaries could be expected to express altered maturation rates, under the control of genotypically dissimilar cumulus cells from the beginning of oocyte development. However, the results of this study do not show any such influence of cumulus cells. All potentially CBA oocytes extruded their polar body before ovulation, although even in CBA females some oocytes with delayed polar body extrusion were observed. Among $\mathrm{KE}$ oocytes of chimaeric females, a few extruded their polar body $10 \mathrm{~h}$ after hCG administration but the proportion of these did not differ from that in the pure KE strain.

Until now, explorations of possible reciprocal influences of cells of contrasting genotype in chimaeric mice have shown large autonomy of each cell genotype. The examination of nine different genes in chimaeric mice has indicated that the germ cells had not been in any way modified by their intimate association with germ cells and somatic cells of contrasting genotype (McLaren, 1975). The XX germ cells in $X X-X Y$ chimaeric testes enter meiotic prophase at the same time as these in non-chimaeric ovaries, that is, before birth (McLaren et al., 1972). Some parameters of sperm head shape, sperm abnormalities and the fertilizing capacity of mouse 
spermatozoa developing in a chimaeric testis have been expressed autonomously (Burgoyne, 1975; Krzanowska et al., 1991).

The present results show that maturation rate, cytoplasmic granule deposition and the sensitivity of the zona pellucida to enzymes are also largely autonomously determined by the oocyte itself.

The author is grateful to $\mathrm{H}$. Krzanowska for critical reading and discussing of the manuscript and to $\mathrm{M}$. Lenartowicz for making and analysing the chromosome preparations of bone marrow. This work was supported by Grant IZ/BW/G/95 from the Institute of Zoology, Jagiellonian University, Cracow.

\section{References}

Bowman P and McLaren A (1970) Viability and growth of mouse embryos after in vitro culture and fusion Journal of Embryology and Experimental Morphology $23693-704$

Burgoyne PS (1975) Sperm phenotype and its relationship to somatic and germ line genotype: a study using mouse aggregation chimaeras Developmental Biology 44 67-76

Dong J, Albertini DF, Nishimori K, Kumar TR, Lu N and Matzuk MM (1996) Growth differentiation factor-9 is required during early ovarian folliculogenesis Nature 383 531-535

Eppig JJ (1982) The relationship between cumulus cell-oocyte coupling, oocyte meiotic maturation and cumulus expansion Developmental Biology $\mathbf{8 9}$ 268-272

Eppig JJ, Freter RR, Ward-Beiley PF and Shultz RM (1983) Inhibition of oocyte maturation in the mouse: participation of CAMP, steroid hormones and putative maturation-inhibitory factor Developmental Biology 100 39-49

Evans EP, Ford CE and Lyon MF (1977) Direct evidence of the capacity of the $X Y$ germ cell in the mouse to become an oocyte Nature $267430-431$

Festing MF (1993) Origins and characteristics of inbred strains of mice Mouse Genome 91 393-509

Ford CE, Evans EP, Burtenshaw MD, Clegg HM, Tuffrey M and Barnes RD (1975) A functional 'sex-reversed' oocyte in the mouse Proceedings of the Royal Society of London Series B 190 1-7

Gearhart J and Oster-Granite L (1981) Reproduction in a population of chimaeric mice: relationship of chromosomal sex to functional germ cells and proportions of chimaeric components in several tissues Biology of Reproduction 24 713-722

Gilula NB, Epstain ML and Beers WH (1978) Cell-to-cell communication and ovulation: a study of the cumulus-oocyte complex Journal of Cell Biology $\mathbf{7 8}$ 58-75

Harris H and Hopkinson DA (1976) Handbook of Enzyme Electrophoresis in Human Genetics North-Holland Publishing Corporation, Amsterdam

lannaccone PM, Evans EP and Burtenshaw MD (1985) Chromosomal sex and distribution of functional germ cells in a series of chimaeric mice Experimental Cell Research 156 471-477
Kaleta E (1977) Influence of genetic factors on the fertilization of mouse ova in vitro. Journal of Reproduction and Fertility 51 375-381

Kaleta E and Majewska I (1979) Inheritance of solubility properties of the zona pellucida of mouse oocytes Genetica Polonica 20 257-263

Kaleta E and Polak Z (1978) Solubility properties of the zona pellucida of mouse oocytes from inbred strains differing in the number of cortical granules Zwierzeta Laboratoryjne 15 53-61

Krzanowska H (1970) Relation between fertilization rate and penetration of eggs by supplementary spermatozoa in different mouse strains and crosses Journal of Reproduction and Fertility 22 199-204

Krzanowska H (1972) Rapidity of removal in vitro of the cumulus oophorus and zona pellucida in different strains of mice Journal of Reproduction and Fertility $317 \cdots 14$

Krzanowska H, Lorenc E, Koncewicz A and Lipina B (1984) The rate of maturation and fertility of oocytes in $\mathrm{KE}$ and $\mathrm{CBA} / \mathrm{Kw}$ female mice with induced superovulation Zwierzeta Laboratoryjne 21 3-13

Krzanowska H, Wabik-Śliz B and Rafiński J (1991) Phenotype and fertilizing capacity of spermatozoa of chimaeric mice produced from two strains that differ in sperm quality Journal of Reproduction and Fertility 91 667-676

Lenartowicz M, Koszut U and Wabik-Śliz B (1988) Application of C-band staining method for analysis of XX/XY chimaeras in mice Genetica Polonica 29 161-170

McLaren A (1975) The independence of germ-cell genotype from somatic influence in chimaeric mice Genetical Research (Cambridge) 25 83-87

McLaren A (1976) Mammalian Chimaeras Cambridge University Press, Cambridge

McLaren A (1991) Development of the mammalian gonad: the fate of the supporting cell lineage BioEssays 13 151-155

McLaren A, Chandley AC and Kofman-Alfaro S (1972) A study of meiotic germ cells in the gonads of foetal mouse chimaeras Journal of Embryology and Experimental Morphology 27 515-524

Mintz B (1968) Hermaphroditism, sex chromosomal mosaicism and germ cell selection in allophenic mice Journal of Animal Sciences (Supplement 1) $\mathbf{2 7}$ $51-60$

Polański $\mathrm{Z}$ (1986) In vivo and in vitro maturation rate of oocytes from two strains of mice Journal of Reproduction and Fertility 78 103-109

Racowsky C and Satterlie RA (1985) Metabolic, fluorescent dye and electrical coupling between hamster oocytes and cumulus cells during meiotic maturation in vivo and in vitro. Developmental Biology 108 191-202

Rafiński J and Krzanowska H (1985) Electrophoretic variants of GPI and ICD in inbred strains of mice: $\mathrm{KE}, \mathrm{KP}, \mathrm{CBA} / \mathrm{Kw}$ and $\mathrm{C} 57 \mathrm{BL} / \mathrm{Kw}$ Zwierzefta Laboratoryjne 22 59-64

Schultz RM, Montgomery RR, Ward-Bailey P and Eppig JJ (1983) Regulation of oocyte maturation in the mouse: possible roles of intercellular communication, CAMP and testosterone Developmental Biology 95 294-304

Wabik-Śliz B (1979) Number of cortical granules in mouse oocytes from inbred strains differing in efficiency of fertilization Biology of Reproduction 21 89-97

Wabik-Śliz B (1986) Comparison of some properties of oocytes segregating in $\mathrm{F}_{2}$ hybrids between $\mathrm{KE}$ and $\mathrm{CBA} / \mathrm{Kw}$ inbred strains of mice Gamete Research $15 \quad 87-94$ 